\title{
Clinical and Therapeutic Aspects of Temporomandibular Ankylosis at the Conakry Teaching Hospital
}

\author{
Oumar Raphiou Diallo*, Alhassane Conde, Ibrahima Diallo, Mamadou Saliou Diallo \\ Department of Odontostomatology and Maxillofacial Surgery Conakry Teaching Hospital Guinea, Conakry, Guinea \\ Email: *rafioumajid@yahoo.fr
}

How to cite this paper: Diallo, O.R., Conde, A., Diallo, I. and Diallo, M.S. (2022) Clinical and Therapeutic Aspects of Temporomandibular Ankylosis at the Conakry Teaching Hospital. Open Journal of Stomatology, $12,1-9$.

https://doi.org/10.4236/ojst.2021.121001

Received: November 5, 2021

Accepted: December 28, 2021

Published: December 31, 2021

Copyright ( 2022 by author(s) and Scientific Research Publishing Inc. This work is licensed under the Creative Commons Attribution International License (CC BY 4.0).

http://creativecommons.org/licenses/by/4.0/

\begin{abstract}
Introduction: Temporomandibular joint ankylosis (TMJA) is a fusion of joint surfaces by fibrous or bone tissue and the resulting limitation of mouth opening. The objectives of this study were to determine the frequency of TMJA, describe the clinical aspects and assess management. Materials and Method: It was a retrospective study that was carried out in the Department of Odontostomatology and Maxillofacial Surgery of Donka National Hospital for a period of 5 years (January 2016 to December 2020). Included were all records of inpatients and managed cases of TMJA during the study period. Sociodemographic, clinical and therapeutic variables were analyzed. Results: During the study 13 TMJA cases were collected with the frequency of $0.47 \%$. The age group 1 - 9 was the most affected (61.54\%) with extremes of 4 and 28 years. Men were the most concerned (53.87\%). Restriction of mouth opening was the main reason for consultation (69.23\%). The etiologies of ankylosis were dominated by infection including cellulitis of dental origin (53.85\%) followed by facial trauma (30.77\%). Arthroplasty was the most commonly used technique (73\%), two cases of recurrence were noted (15.38\%). Conclusion: TMJA affects mainly children and the etiology is dominated by cellulite of dental origin hence the interest of sensitization of the population for early management of oral diseases.
\end{abstract}

\section{Keywords}

Ankylosis, Temporomandibular Joint, Clinical, Therapeutic, Teaching Hospital, Conakry

\section{Introduction}

Temporomandibular joint ankylosis (TMJA) is a permanent constriction of the 
jaws by fibrous or bone joint welding, unilateral or bilateral. It is expressed by the inability to lower the mandible normally and is responsible for functional and morphological disorders [1]. It is a pathology of all ages, but mainly that of children. Well known to older authors now almost forgotten in developed countries, TMJA is still relevant in developing countries [2]. While in developing countries infection is the main cause, the most common etiology found in developed countries is trauma, in the context of condyle fracture. Other etiologies are also encountered: inflammatory (rheumatoid arthritis and ankylosing spondylitis in particular) and congenital (very rare) [2] [3].

The overall incidence of TMJA is decreasing mainly due to better management of fractures of the condylar region [3]. However, it remains important in some countries and constitutes a growing public health problem among children, especially in sub-Saharan Africa where the incidence in some countries is estimated at $12 / 1000$ cases [4].

Clinically, in addition to the impossibility of mouth opening, facial asymmetry, micrognathia and occlusal disturbances can be noted [5]. TMJA is a condition of varying severity that can be functionally, morphologically and psychologically disabling [6].

Therapeutically, this condition poses three major problems: freeing the mandibular movements while avoiding recurrence; restoring the masticatory function while respecting the occlusion; correcting the induced deformations [1].

The management of TMJA is primarily surgical. It consists of resection of the ankylosis block, associated with a unilateral or bilateral coronoidectomy. Resection of the block can be compensated by the interposition of a temporal fascia flap, a chondrocostal graft or a prosthesis depending on the loss of height and the impact on the dental joint. However, regardless of the technique, the effectiveness of treatment for TMJA is relative due to the risk of disease recurrence [3]. Zhi K et al. [7] in 2009 reported 7.14\% recurrence after resection of ankylosis block. TMJA surgery is also associated with potential complications, including facial nerve palsy and occlusal disorders [8]. The frequency of occurrence of permanent facial paralysis varies between $9 \%$ and $18 \%$, that of a temporary deficit between $1.5 \%$ and $37 \%$ [9] [10].

No study having been published in Guinea on TMJA and because of the aesthetic and functional problems they cause, it seemed opportune to carry out this study, the objectives of which were to determine the frequency of TMJA; describe the clinical features and their treatment.

\section{Material and Method}

This was a descriptive retrospective study that took place in the Odontostomatology and Maxillofacial Surgery department of Donka National Hospital over a period of 5 years (January 2016 to December 2020). All the files of hospitalized patients treated for TMJA and who benefited from a follow-up of at least 6 months were included. Incomplete records and those of patients hospitalized for 
TMJA but who did not receive treatment were excluded. Sociodemographic, clinical and therapeutic variables were evaluated.

The type of ankylosis was defined taking into account the Topazian classification [11]. This author classifies TMJA into 3 types depending on the extent of the bone block. These are: Type I: ankylosis block affects the condyle; Type II: affects the condyle and sigmoid notch; Type III: This is the most extensive form since it involves the condyle, the sigmoid notch, and the coronoid process.

Surgical treatment consisted of resection of the ankylosis block under general anesthesia, followed by removal and interposition of a flap of the ipsilateral temporalis muscle. It was associated, depending on the case, with bilateral coronoidectomy and geniopalatine. The patients were followed for a period of 6 months. During this follow-up measurements of the amplitude of the mouth opening were made using a caliper.

The outcome was considered good in patients presenting after 6 months of postoperative follow-up, an amplitude of the mouth opening between 30 - 40 $\mathrm{mm}$. The result was fair if the mouth opening was less than or equal to $20 \mathrm{~mm}$. It was bad if the opening was less than $5 \mathrm{~mm}$ (these cases were considered recurrences).

Data collection and analysis: The survey forms were completed manually. Word processing was performed using Microsoft Word software, data analysis was performed using Microsoft Excel and SPSS 21 software.

The confidentiality of the data and the identity of the patients were respected and the ethical approval has been obtained from the Ethics Committee of the Ministry of Health and written consent was obtained from all patients.

\section{Results}

Out of a total of 2279 hospitalized patient files, 13 presented with TMJA, ie a frequency of $0.4 \%$. Patients aged $1-9$ years were more represented $n=8$ (61.54\%). The mean age of the patients was 12 years with extremes ranging from 4 to 28 years. In 7 cases, these were male patients, i.e. $53.84 \%$. The pupils were concerned in $92.30 \%(\mathrm{n}=12)$ (Table 1$)$. The duration of the disease was 3 years in 1 case $(7.70 \%)$, between 3 - 5 years in 3 cases (23.07\%). In $38.46 \%$ of cases this duration was between 5 - 10 years, it was greater than 10 in 4 cases (30.77\%).

The consultation period varied between 3 years and 10 years and more with an average of 6.12 years.

According to the previous treatment carried out, $61.54 \%$ of the cases $(n=8)$, of the patients had undergone a treatment by a traditional practitioner, in 3 cases (23.08\%) the treatment was carried out in a health structure and 2 patients had not performed any treatment before. The site of ankylosis was unilateral in 5 cases $(38.46 \%)$ and bilateral in 8 cases, ie $61.53 \%$. In 7 patients $(53.85 \%)$ the etiology of ankylosis was odontogenic cellulitis, in 4 cases $(30.77 \%)$ it was trauma and noma was the cause in 2 cases $(15.38 \%)$. 
The limitation of the mouth opening was observed in all the patients followed by a latero-deviation of the mandible in 7 cases, i.e. $53.85 \%$ and 8 patients $(61.53 \%)$ presented a profile of birds (Figures $1(\mathrm{a})-(\mathrm{c})$ ). All patients had a CT scan (Figures 2(a)-(c)) and a preoperative laboratory assessment (the result of which did not revealed any particularities). Topazian type II was observed in 7 patients, i.e. $53.85 \%$ (Table 2).

Surgically, all patients had undergone resection of the ankylosis block. This resection was associated in 11 cases $(84.61 \%)$ with a bilateral coronoidectomy followed by the interposition of a flap of the ipsilateral temporalis muscle. Among these 11 patients, 5 (or 38.46\%) also benefited from a genioplasty. The evolution was considered good in 10 patients, i.e. $76.93 \%$ (Figures $3(\mathrm{a})-(\mathrm{c})$ ); it was fair in 1

Table 1. Socio-demographic characteristics of the patients.

\begin{tabular}{ccc}
\hline Socio-demographic characteristics & Number & Percentage \\
Sex & 7 & 53.84 \\
Male & 6 & 46.14 \\
Female & & \\
Age & 8 & 61.54 \\
1 - 9 years & 3 & 23.07 \\
10 - 19 years & 2 & 15.39 \\
20 - 29 years & & \\
Occupation & 12 & 92.30 \\
Pupil/Students & 1 & 7.70 \\
Household & & \\
Origin & & 76.92 \\
Rural & 10 & 23.08 \\
Urban & 3 & \\
\hline
\end{tabular}

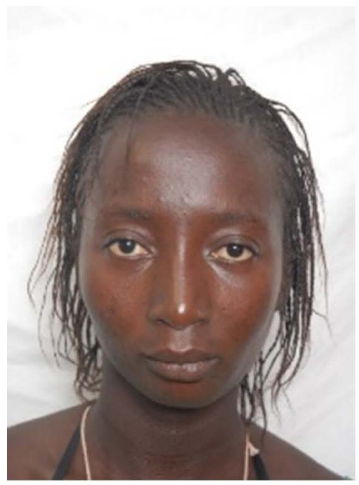

(a)

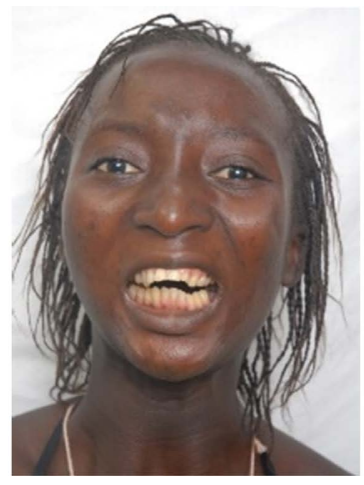

(b)

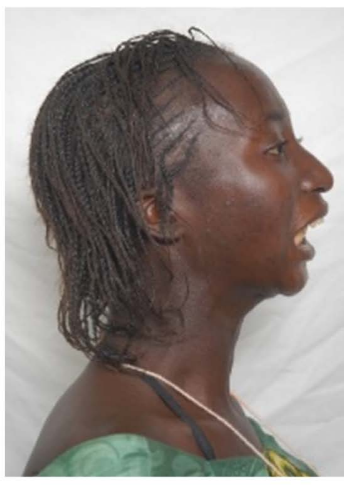

(c)

Figure 1. (a) Patient (frontal view) before the operation; (b) Patient (frontal view, open mouth); (c) Patient (profile view, open mouth with the profile of birds) (with erasure of the chin, recoils of the mandible, limitation of the mouth opening). 


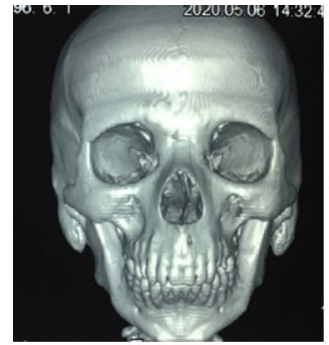

(a)

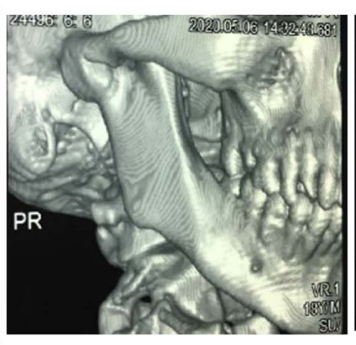

(b)

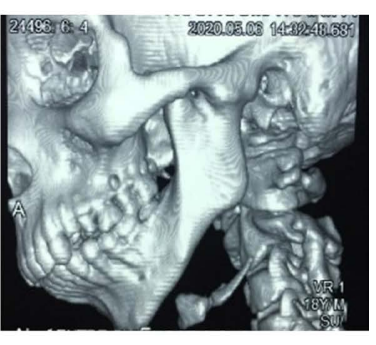

(c)

Figure 2. (a) Cranio-facial CT scan (front view); (b) Cranio-facial CT scan (right side view); (c) Cranio-facial CT scan, left profile view showing constriction of the jaws, welding of the condyles and coronoid processes with the temporal bone.

Table 2. Distribution of patients according to the Topazian classification.

\begin{tabular}{ccc}
\hline Classification & Number & Percentage \\
\hline Type I & 2 & 15.38 \\
Type II & 7 & 53.85 \\
Type III & 4 & 30.77 \\
Total & 13 & 100.00 \\
\hline
\end{tabular}

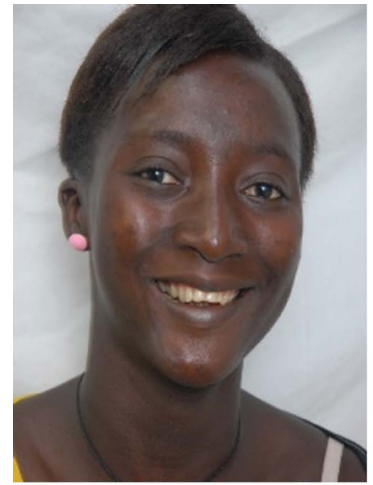

(a)

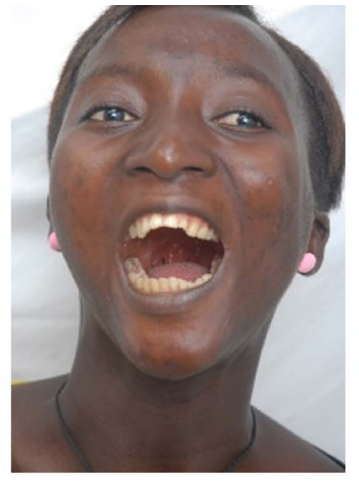

(b)

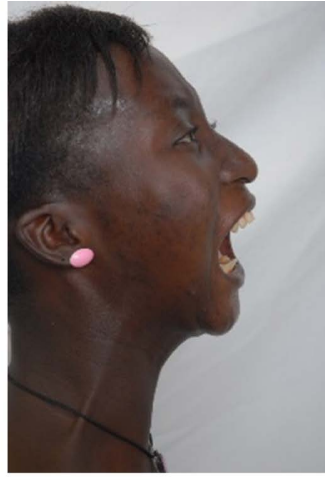

(c)

Figure 3. Patient 6 months after operation with normal opening of the month. (a) Patient (frontal view); (b) Patient (frontal view, open mouth); (c) Patient (profile view, open mouth).

patient $(7.69 \%)$ and in 2 cases, i.e. $15.38 \%$, the result was poor and these patients were considered as cases of relapse of ankylosis.

\section{Discussion}

During this study, 13 files of TMJA out of a total of 2779 files were collected, ie a frequency of $0.47 \%$. This relatively low frequency could be explained by the low attendance of hospitals by patients linked to lack of information, illiteracy and recourse to traditional medicine. In France in 2006, Poirier F et al. [12] reported on 94 mandibular disorders 1 case of TMJA (1.06\%). The overall incidence of ankylosis is decreasing in economically advanced countries, mainly due to better management of fractures of the condylar region [13]. In this study, the average age of the patients was 12 years with extremes of 4 and 28 years. The age group 
of 1 - 9 years was the most affected with a frequency of $61.53 \%$. TMJA is a pathology of all ages but mainly that of children who, due to their growing state, have a greater propensity to callus formation and ankylosis than adults [13]. Erol B et al. [14] noted in a series of 59 patients, $78 \%$ of patients aged 15 and over. On the other hand, Sankar D et al. [15] in India in 2016 reported in their study that patients over 20 years of age were the most affected (48\%). Male predominance was noted with $53.85 \%$ of cases. The predominance of one sex over the other varies depending on the series. While some authors [2] [16] [17] report a male predominance as observed in this study, others [4] [12] [14] note a female predominance. Students were the most affected, $92.31 \%$ of cases. The predominance of pupils could be due to the fact that it is a disease which mainly affects children.

Patients who consulted between 5-10 years of disease progression were the most frequent $38.46 \%(n=5)$. The first consultation time varied between 3 years and 10 years (average 6.12 years). This result corroborates that found by Béogo $\mathrm{R}$ et al. [8] who reported that the consultation time varied between 5 months and 13 years (mean 6.4 years). The lack of information and the low socio-economic level of the population are all factors that may explain this delay in consultation.

The main reason for consultation was limitation of mouth opening in $69.23 \%$. In Nigeria Bello SA et al. [4] in 2012 found in a total of 23 patients, 15 cases of limited mouth opening (65.22\%). In this series, the majority of patients, ie $61.54 \%$ of cases, had recourse to traditional therapy. The high frequency of patients having resorted to traditional medicine is explained on the one hand by illiteracy and on the other hand by the lack of information on the disease and the existence of specialized centers for its treatment. Etiologically, odontogenic cellulitis was the cause of the disease in $46.15 \%$ of cases. Infectious causes are mainly reported in series from developing countries [2] [5], however the traumatic etiology is mainly reported in series from developed countries. In Germany, Gundlach KK [18] in 2010 reported that trauma accounted for $88 \%$ of the causes of TMJA. Bilateral localization was found in $61.54 \%(\mathrm{n}=8)$ of cases. On the other hand, Vasconcelos BC et al. [19] noted that unilateral localization was more frequent with a ratio of 1.5 .

The treatment of TMJA is primarily surgical. Interposition material is necessary to prevent recurrence after joint replacement, and this particular aspect of treatment has been the subject of much discussion. Thus a variety of interposition materials have been used, including temporalis muscle and fascia, dermis, atrial cartilage, fascia lata, fat, silastic, silicone, and various metals [20] [21] [22] [23].

The most commonly used interposition material is the temporalis muscle flap. In this series, resection of the ankylosis block associated with interposition of a temporal muscle flap and coronoidectomy was performed in 11 patients $(84.61 \%)$. The temporal myofascial flap is a good interposition material, due to its good vascular supply, its anatomical proximity and its adequate thickness [24]. The effectiveness of this method has been reported by various authors [24] [25] 
[26].

Although the evolution was considered good in 10 patients (76.93\%), with a mouth opening at 6 months of between 30 and $40 \mathrm{~mm}, 2$ cases of recurrence were noted, ie 15.38\%. Béogo R et al. [8] in 2013 recorded 20\% of recurrences. Benateau $\mathrm{H}$ et al. [3] reported that recurrence is the most common complication with frequencies ranging from 0 to $30 \%$. The literature is difficult to analyze, with varying timelines and definitions for both success and recurrence of ankylosis. In general, mandibular ankylosis is considered difficult to manage, and for some, an amplitude of the mouth opening at more than one year of greater than 30 $\mathrm{mm}$ should be considered excellent [27]. Recurrences usually occur due to lack of persistence in rehabilitation, and usually in the first 6 months postoperatively [2].

The limitations of this study were the incomplete patient records and the lack of funds to carry out postoperative CT scan.

\section{Conclusion}

Temporomandibular joint ankylosis is a condition that predominantly affects male children. The main etiologies are infections (cellulitis, noma) and maxillofacial trauma. The best prevention of this pathology and its recurrences requires actions for adequate and early management of oral diseases and their complications, and postoperative follow-up based on rehabilitation.

\section{Conflicts of Interest}

The authors declare no conflicts of interest regarding the publication of this paper.

\section{References}

[1] Spomiak-Tutak, K., Janiszewska-Olszowska, J. and Kowalczyk, R. (2011) Management of Temporomandibular Ankylosis Compromise or Individualization-A Literature Review. Medical Science Monitor, 17, RA111-116. https://doi.org/10.12659/MSM.881755

[2] Chidzonga, M.M. (1999) Temporomandibular Joint Ankylosis: Review of ThirtyTwo Cases. British. Journal of Oral and Maxillofacial Surgery, 37, 123-126. https://doi.org/10.1054/bjom.1997.0089

[3] Benateau, H., Chatellier, A., Caillot, A., Diep, D., Kun-Darbois, J.D. and Veyssiere, A. (2016) L'ankylose Temporomandibulaire. Revue de Stomatologie, de Chirurgie Maxillo-faciale et de Chirurgie Orale, 117, 245-255.

[4] Bello, S.A., Olokun, B.A., Olaitan, A.A. and Ajike, S.O. (2012) A Etiology and Presentation of Ankylosis of the Temporomandibular Joint: Report of 23 Cases from Abuja, Nigeria. British Journal of Oral and Maxillofacial Surgery, 50, 80-84. https://doi.org/10.1016/j.bjoms.2010.12.006

[5] Saeed, N.R. and Kent, J.N. (2003) A Retrospective Study of the Costochondral Graft in TMJ Reconstruction. International Journal of Oral and Maxillofacial Surgery, 32, 606-609. https://doi.org/10.1054/ijom.2003.0418

[6] Roychoudhury, A., Parkash, H. and Trikha, A. (1999) Functional Restoration by Gap 
Arthroplasty in Temporomandibular Joint Ankylosis: A Report of 50 Cases. Oral Surgery, Oral Medicine, Oral Pathology, and Oral Radiology, 87, 166-169. https://doi.org/10.1016/S1079-2104(99)70267-2

[7] Zhi, K., Ren, W., Zhou, H., Gao, L. and Zhao, L. (2009) Management of Temporomandibular Joint Ankylosis: 11 Years Clinical Experience. Oral Surgery, Oral Medicine, Oral Pathology, Oral Radiology, and Endodontology, 108, 687-692. https://doi.org/10.1016/j.tripleo.2009.06.041

[8] Beogo, R., Gandema, S., Traore, I., Coulibaly, T.A., Millogo, M. and Ouoba, K. (2013) L'ankylose temporomandibulaire: À propos de 17 patients et revue de la littérature. Mali Medical, 28, 10-14.

[9] Weinberg, S. and Kryshtalskyj, B. (1992) Facial Nerve Function Following Temporomandibular Joint Surgery Using the Preauricular Approach. Journal of Oral and Maxillofacial Surgery, 50, 1048-1051. https://doi.org/10.1016/0278-2391(92)90488-L

[10] Politi, M., Toro, C., Cian, R., Costa, F. and Robiony, M. (2004) The Deep Subfascial Approach to the Temporomandibular Joint. Journal of Oral and Maxillofacial Surgery, 62, 1097-1102. https://doi.org/10.1016/j.joms.2003.10.013

[11] Topazian, R.G. (1964) Etiology of Ankyloses of the Temporomandibular Joint: Analysis of 44 Cases. Journal of Oral Surgery, Anesthesia, and Hospital Dental Service, 22, 227-233.

[12] Poirier, F., Blanchereau, C., Francfort, E., Agostini, P., Petavy, A., Khorshid, M., et al. (2006) Prise en charge chirurgicale de l'articulation temporomandibulaire: À propos de 94 cas. Revue de Stomatologie et de Chirurgie Maxillo-faciale, 107, 436-440. https://doi.org/10.1016/S0035-1768(06)77083-8

[13] He, D., Yang, C., Chen, M., Zhang, X., Qiu, Y., et al. (2011) Traumatic Temporomandibular Joint Ankylosis: Our Classification and Treatment Experience. Journal of Oral and Maxillofacial Surgery, 69, 1600-1607.

https://doi.org/10.1016/j.joms.2010.07.070

[14] Erol, B., Tanrikulu, R. and Görgün, B. (2006) A Clinical Study on Ankylosis of the Temporomandibular Joint. Journal of Cranio-Maxillofacial Surgery, 34, 100-106. https://doi.org/10.1016/j.jcms.2005.07.008

[15] Sankar, D., Krishnan, R., Veerabahu, M., Vikraman, B.P. and Nathan, J.A. (2016) Retrospective Evaluation of Airway Management with Blind Awake Intubation in Temporomandibular Joint Ankylosis Patients: A Review of 48 Cases. Annals of Maxillofacial Surgery, 6, 54-57. https://doi.org/10.4103/2231-0746.186126

[16] Valentini, V., Vetrano, S., Agrillo, A., Torroni, A., Fabriani, F. and Ianetti, G. (2002) Surgical Treatment of TMJ Ankylosis: Our Experience (60 Cases). Journal of Craniofacial Surgery, 13, 59-67. https://doi.org/10.1097/00001665-200201000-00013

[17] Shashikiran, N.D., Reddy, S.V., Patil, R. and Yavagal, G. (2005) Management of Temporo-Mandibular Joint Ankylosis in Growing Children. Journal of Indian Society of Pedodontics and Preventive Dentistry, 23, 35-37. https://doi.org/10.4103/0970-4388.16025

[18] Gundlach, K.K.H. (2010) Ankylosis of the Temporomandibular Joint. Journal of Cranio-Maxillofacial Surgery, 38, 122-130. https://doi.org/10.1016/j.jcms.2009.04.006

[19] Vasconcelos, B.C.E., Bessa-Nogueira, R.V. and Cypriano, R.V. (2006) Treatment of Temporomandibular Joint Ankylosis by Gap Arthroplasty. Medicina Oral, Patología Oral y Cirugía Bucal, 11, E66-E69.

[20] Maki, M.H. and Al-Assaf, D.A. (2008) Surgical Management of Temporomandibular Joint Ankylosis. Journal of Craniofacial Surgery, 19, 1583-1588. 
https://doi.org/10.1097/SCS.0b013e31818ac12c

[21] Manfredini, D., Bucci, M.B. and Guarda-Nardini, L. (2009) Temporomandibular Joint Bilateral Post-Traumatic Ankylosis: A Report of a Case Treated with Inter Positional Arthroplasty. Minerva Stomatologica, 58, 35-42

[22] Mani, V. and Panda, A.K. (2003) Versatility of Temporalis myofascial Flap in Maxillofacial Reconstruction-Analysis of 30 Cases. Journal of Oral and Maxillofacial Surgery, 32, 368-372. https://doi.org/10.1054/ijom.2002.0349

[23] Schliephake, H., Schmelzesien, R., Maschek, H. and Haese, M. (1999) Long-Term Results of the Use of Silicone Sheets after Diskectomy in the Temporomandibular Joint: Clinical, Radiographic and Histopathologic Findings. International Journal of Oral \& Maxillofacial Surgery, 28, 323-329.

https://doi.org/10.1034/j.1399-0020.1999.285280501.x

[24] Kim, J.Y., Kim, J.Y., Jung, Y.S. and Nam, W. (2014) Treatment of Temporomandibular Joint Reankylosis by Submandibular Anchorage Technique with Temporalis Myofascial Flap. Maxillofacial Plastic and Reconstructive Surgery, 36, 78-83.

https://doi.org/10.14402/jkamprs.2014.36.2.78

[25] Guruprasad, Y., Dinesh, S.C. and Cariappa, K.M. (2010) A Retrospective Study of Temporalis Muscle and Fascia Flap in Treatment of TMJ Ankylosis. Journal of Maxillofacial and Oral Surgery, 9, 363-368.

https://doi.org/10.1007/s12663-010-0139-Z

[26] Katsnelson, A., Markiewicz, M.R., Keith, D.A. and Dodson, T.B. (2012) Operative Management of Temporomandibular Joint Ankylosis: A Systematic Review and Meta-Analysis. Journal of Oral and Maxillofacial Surgery, 70, 531-536. https://doi.org/10.1016/j.joms.2011.10.003

[27] Zins, J.E., Smith, J.D. and James, D.R. (1989) Surgical Correction of Temporomandibular Joint Ankylosis. Clinics in Plastic Surgery, 16, 725-732. https://doi.org/10.1016/S0094-1298(20)31294-3 